\title{
A DISCRETE EVENT SIMULATION MODEL OF ASPHALT PAVING OPERATIONS
}

\author{
Ramzi Labban \\ Simaan AbouRizk \\ Hole School of Construction Engineering \\ and Management \\ Department of Civil and Environmental \\ Engineering \\ University of Alberta \\ 3-015 Markin/CNRL \\ Natural Resources Engineering Facility \\ Edmonton, Alberta, T6G 2W2, CANADA
}

\author{
Zuhair Haddad \\ Amr Elsersy \\ Consolidated Contractors Group \\ 62B Kifissias Avenue \\ Maroussi, 15125 Athens, GREECE
}

\begin{abstract}
Although research into simulation of construction continues to advance and thrive in the academic world, application of simulation in the construction industry remains limited. Stakeholders on construction projects have yet to adopt simulation as their default tool of choice for managing large complex projects, instead of traditional techniques, which are often inadequate. This paper describes the building of an asphalt paving simulator, as an example of the rigor and effort required in developing construction simulation models, and then briefly describes an alternative model building method currently being researched which may potentially make it easier and faster for stakeholders to quickly build simulation models on construction projects.
\end{abstract}

\section{INTRODUCTION}

As construction projects become large, complex and tough to manage using traditional techniques, computer simulation can be used effectively to design and analyze construction processes regardless of the complexity or size (Abourizk 2010).

Computer simulation models can be built to characterize the construction activities of a scope of work ranging from a full blown large and complex project to a sub-area of an industrial facility or to a floor or room of a building. The process of building a simulation model includes four distinct phases: product abstraction phase, process abstraction and modeling phase, experimentation phase, and decision making phase (Abourizk 2010). The effort and technical expertise needed to build a simulation model and then run experiments compared with the uniqueness and relatively short life cycle of a construction project contribute to the slow adoption of simulation by the industry (Mohamed 2005).

While building a new model, simulation practitioners find themselves going through the full fourphase process in its entirety. This rigorous and time consuming cycle is typically repeated for every new construction simulation model to be built. Accordingly, when faced with a new situation to analyze or a question to be answered, stakeholders on large and complex projects, even those who are familiar with the usefulness of simulation and value its role, have to make the choice between either using simulation techniques to approach the problem, or resorting to traditional tools. Time permitting and with the right resources and expertise, the choice would be simulation. However, time and know-how lacking - the more prevalent situation, the decision is often to fall back on traditional techniques that would yield a result quickly and with much less effort, even though stakeholders understand the relative inadequacy of the traditional tools. An approach to remedy such a situation would be to diminish the time and skills required to build a simulation model. 
Modeling is the most difficult and the most time-consuming part of simulation (Abourizk 1995). Shortening this process and taking away from it some of the rigor required would enable stakeholders to concentrate on solving the problem they are facing rather than spending their time within a simulation development environment attempting to build a simulation model.

This paper will (1) describe a special purpose simulation model developed to estimate, plan and manage asphalt paving operations, and (2) briefly describe a proposed alternative method currently being research to rapidly build construction simulation models.

\section{ASPHALT PAVING SIMULATION MODEL}

\subsection{Background}

Asphalting operations are a main constituent of road construction projects. Asphalting operations involve numerous interactions between the many participants in the process including the paving machines, trucks, loaders, rollers, asphalt plants, and material sources. Loaders load trucks with aggregate material for the sub-base laying operation. Trucks transfer the sub-base layer material to the paving machine. Trucks form a queue at the paving machine and wait for their turn to unload into the paving machine while it is laying the fill material. Rollers follow the paving machine at an appropriate distance and compress the layers. The same operation is repeated for asphalt. Trucks are loaded with asphalt from the asphalt plants. The trucks then haul the material to the paving machines and form a queue, waiting for their turn to unload the material into the paving machine, which is laying an asphalt base course or wearing course. Appropriate rollers follow the asphalting machine to compress the asphalt layer.

\section{Wearing Course ( 2 layers each with $p$ thickness)}

Base Course (y layers each with $n$ thickness)

Subbase Course ( $x$ layers each with $m$ thickness)

Figure 1: The three layers

Many factors affect the operations and the interactions between the different resources. A main factor in asphalt paving operations is the number and the asphalt laying rate of the asphalt paving machines. The number of paving machines must be sufficient to meet the overall laying speed required to finish the operations on time. Asphalt plants operate at a typical asphalt production rate which governs the amount of asphalt available for the operation. A lower than required asphalt plant production rate will lead to delays in finishing the operation. The number of trucks that can be loaded at the same time, truck loading time, truck load size, truck travel speed, and the distance between the sources and the construction location are among the factors affecting the supply of material to the paving machines. Not enough trucks will lead to delays in the operation.

The most common uses of the asphalting simulator are estimating, planning and managing asphalt operations on a project. It helps determine: (1) the total time required for an asphalting operation; (2) the required asphalt plant production rate (3); the required number of different equipment involved (pavers, rollers, trucks, loaders); and (4) which type of equipment is acting as a bottleneck. 


\subsubsection{Simulator Design and Development}

The simulator was developed to cater to the issues stated above. The first step was the abstraction of the real world situation into a simulation model representing asphalt paving operations including the product and process definitions.

\subsubsection{Product Definitions}

For product definitions, this included building up to three main courses: the sub-base course, the base course and the wearing course. First, we defined the overall length of the paving operation. For each of the courses, we needed to define the width, the number of layers, and the thickness of each layer.

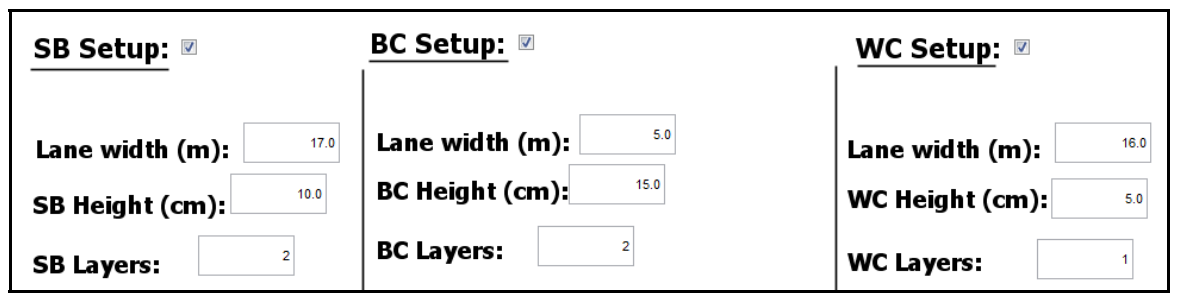

Figure 2: Properties of the three layers

\subsubsection{Process Definitions}

For the process definitions we needed to define the flow of the tasks required to build each of the products and the inter-relationships between the different processes. For each process we needed to identify the resources required (along with all their relevant properties), the material sources including production rates and distances from site, and the team compositions for each layer operation. A large amount of supplementary code was written behind each of the task flows to support the generic nature with which this model was being developed. Changing any of the flow sequences in the model requires changes to be applied to the model through the graphical user interface and to the supplementary code behind the scenes.

\subsection{Sub-base Course}

To represent the sub-base course laying operations, two discrete event simulator flows were implemented. The first is a material delivery flow handling trucking operations from the aggregate source(s) to site and back. The second flow depicts the aggregate laying operations for the $\mathrm{x}$ layers of sub-base course.

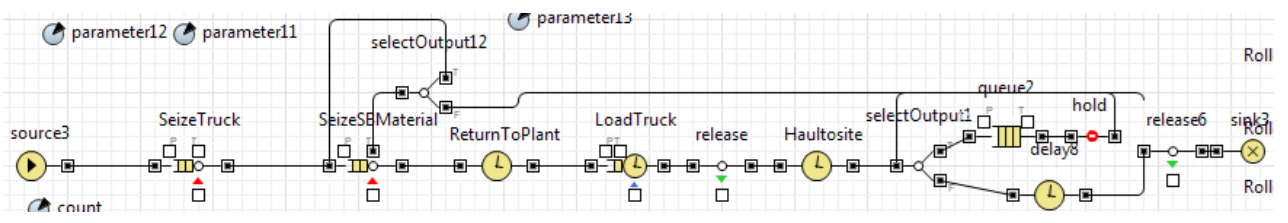

Figure 3: DES flow \#1 - aggregate material delivery to site

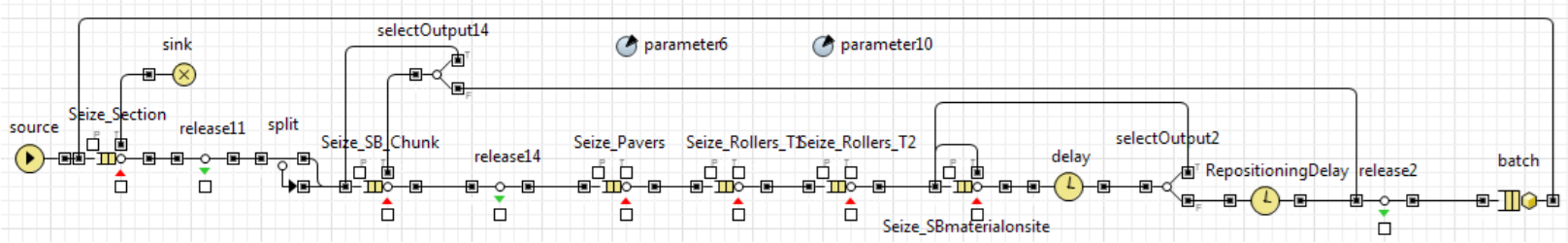

Figure 4: DES flow \#2 - aggregate laying operation 


\subsection{Base Course}

To represent the base course laying operations, two discrete event simulator flows were implemented. The first is a material delivery flow handling trucking operations from the asphalt plant to site and back. The second flow depicts the paving operations for the y layers of base course.

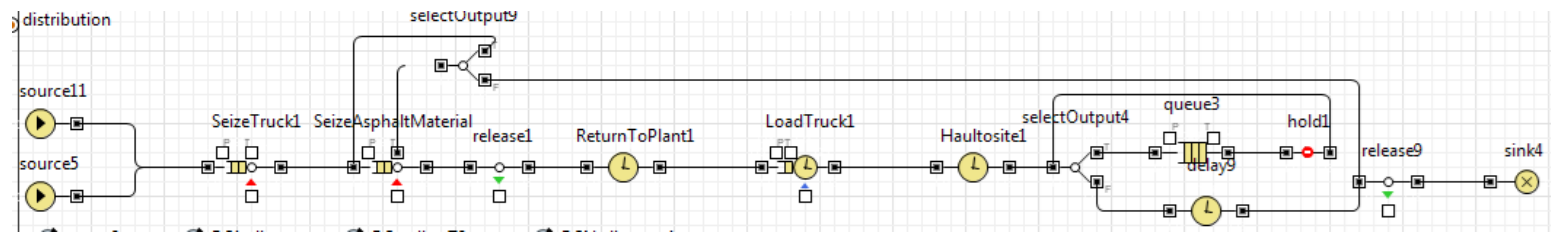

Figure 5: DES flow \#3 - asphalt material delivery to site for base course operation

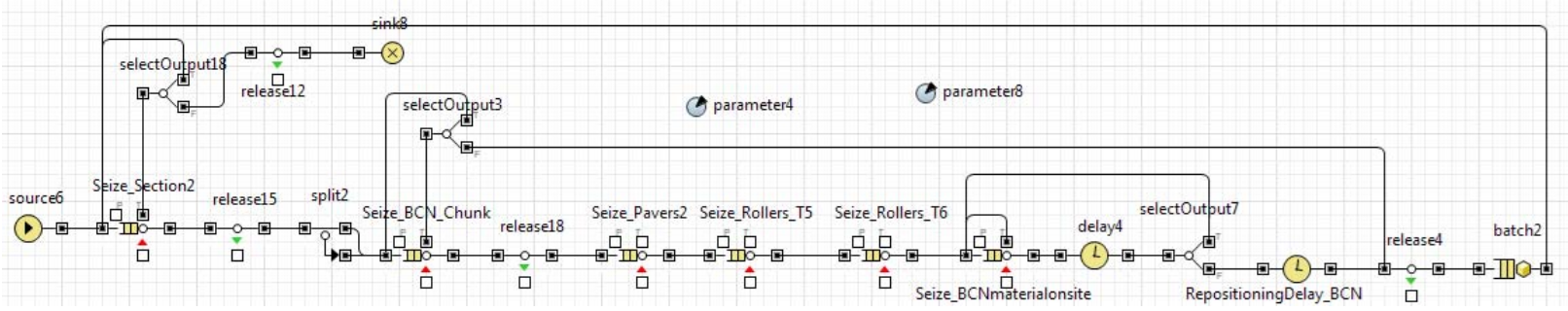

Figure 6: DES flow \#4 - asphalt base course laying

\subsection{Wearing Course}

To represent the wearing course laying operations, two discrete event simulator flows were implemented. The first is a material delivery flow handling trucking operations from the asphalt plant to site and back. The second flow depicts the paving operations for the $\mathrm{z}$ layers of wearing course.

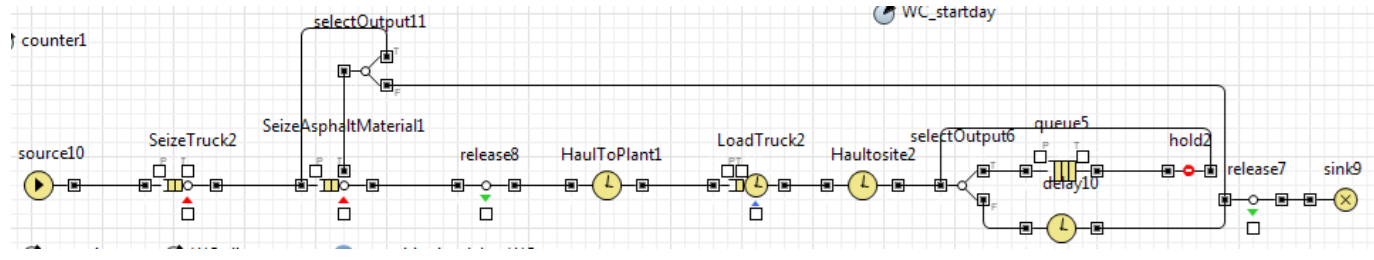

Figure 7: DES flow \#5 - asphalt material delivery to site for wearing course operation

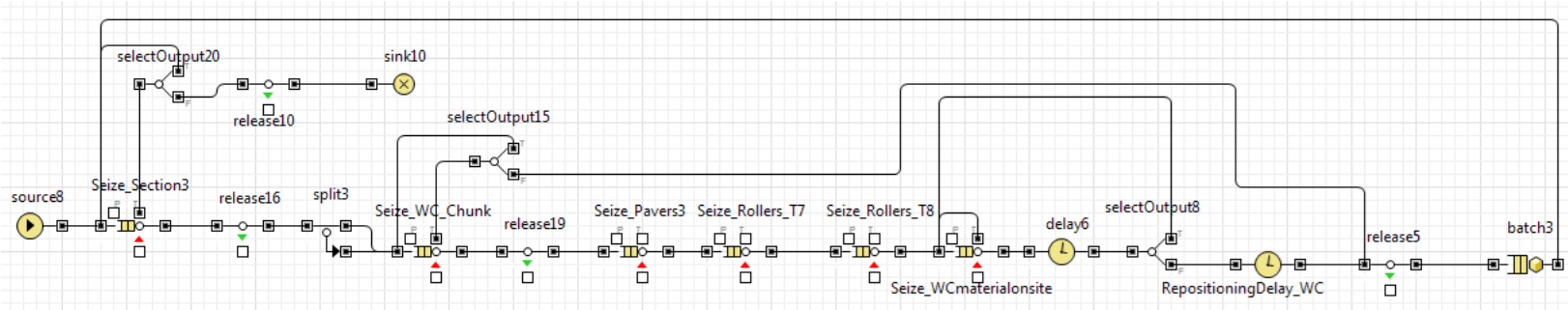

Figure 8: DES flow \#6 - asphalt wearing course laying

\subsection{Asphalt Plant Sources}

The asphalt plant definition interface allows the user to add a record for each asphalt plant to be used in the simulator. Each record contains the asphalt plant production rate, the number and size of hot storages, 
the distance between the plant and site, and the percentage of total asphalt required to be drawn from this plant.

\subsection{Aggregate Sources}

The aggregate sources definition interface allows the user to add a record for each aggregate source to be used in the simulator. Each record contains the aggregate source production rate, the distance between the aggregate source and site, and the percentage of total required aggregate to be drawn from this source.

\subsection{Equipment Selection}

The equipment required for each of the processes is selected through the interface, assigning the appropriate relevant models such as loaders, trucks and pavers.

\begin{tabular}{|c|c|c|c|c|c|c|}
\hline \multicolumn{2}{|c|}{ Loader Setup: } & \multicolumn{2}{|l|}{ Trucks Setup: } & \multicolumn{3}{|c|}{ Paver Setup: } \\
\hline \multicolumn{2}{|c|}{ Type: CAT 950G } & Type: Cat D25D & & Type: & Voegele 1900 & 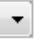 \\
\hline \multirow[t]{2}{*}{ Number: 3} & \multirow[t]{2}{*}{ 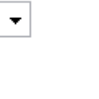 } & Asphalt Trucks: 6 & & \multicolumn{3}{|c|}{ Asphalt Pavers: 2} \\
\hline & & Aggregate Trucks: 6 & $\checkmark$ & \multicolumn{3}{|c|}{ Aggregate Pavers: 2} \\
\hline
\end{tabular}

Figure 9: Selection of equipment

For each process, a model team (crew) of equipment is assembled listing the number of pavers and rollers required. A process may have one or more teams available to do the work.

\begin{tabular}{|c|c|c|c|c|c|}
\hline \multicolumn{2}{|c|}{ SB Team Template: } & \multicolumn{2}{|c|}{ BC Team Template: } & \multicolumn{2}{|c|}{ wC Team Template } \\
\hline \# Pavers: & 1 & \# Pavers: & 1 & \# Pavers: & 1 \\
\hline \# Rollers T1: & 1 & \# Rollers T1 & 2 & \# Rollers T1: & 2 \\
\hline \# Rollers T3: & 4 & \# Rollers T2 & 4 & \# Rollers T2: & 4 \\
\hline
\end{tabular}

Figure 10: Crew building interface

\subsubsection{The Overall Model}

The above pieces come together as in Figure 11 below: (a) a main parameters input module, (b) a main process module, (c) an asphalt plant definition module, (d) an aggregate source definition module, (e) an equipment database module, (f) an outputs module, and (g) an animation module. 


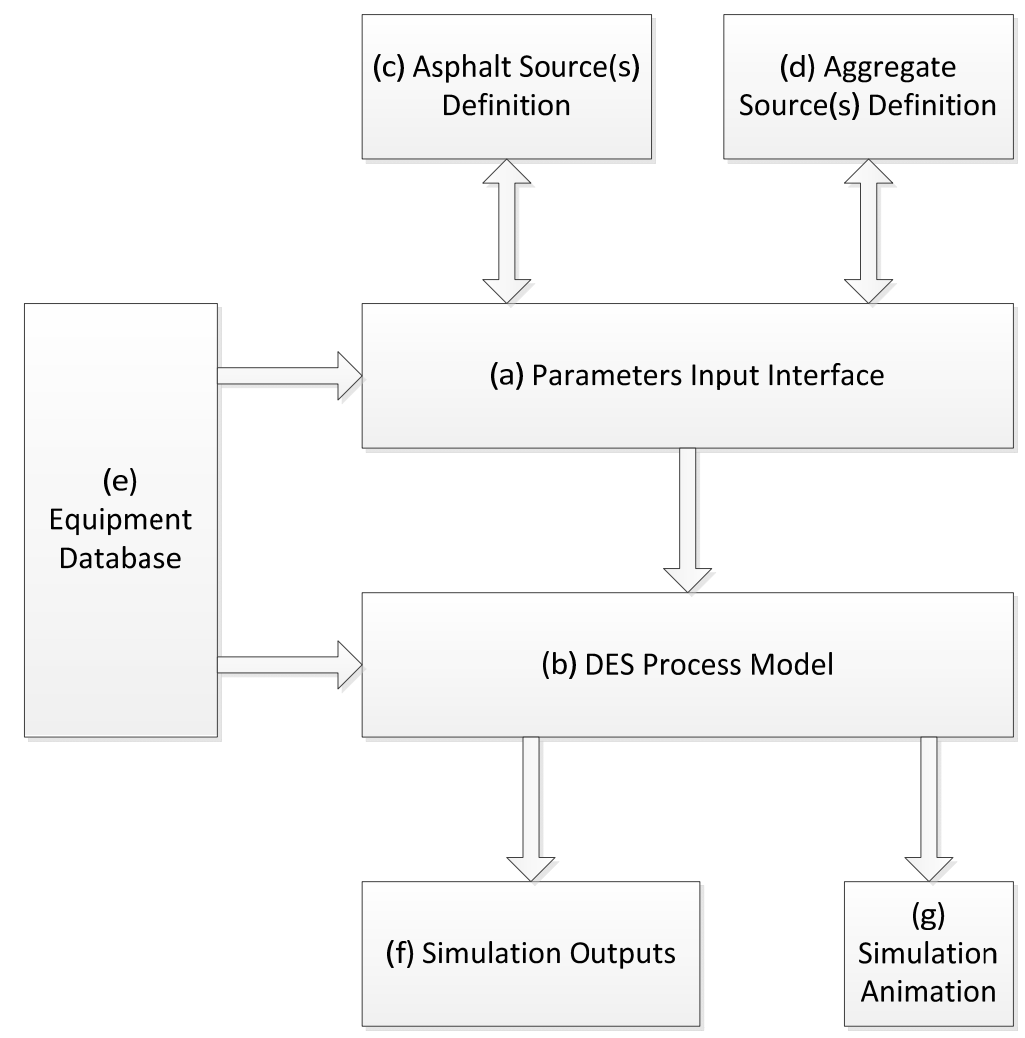

Figure 11: The overall model

The parameters input interface (a) allows the definition of the products and resources and links to the asphalt (c) and aggregate (d) sources definitions. The DES process model (b) incorporates all the simulator flows and supplementary code for the processes. The equipment database (e) contains information about all the relevant equipment types that can be selected for use within the simulator; each piece of equipment in the database carries its productivity norms for the simulator.

The main simulator outputs available during runtime and at the end of the simulation run appear in the simulation outputs (f) module. These include the time required to complete each layer, time required for total completion, equipment idle times, and equipment productivity.

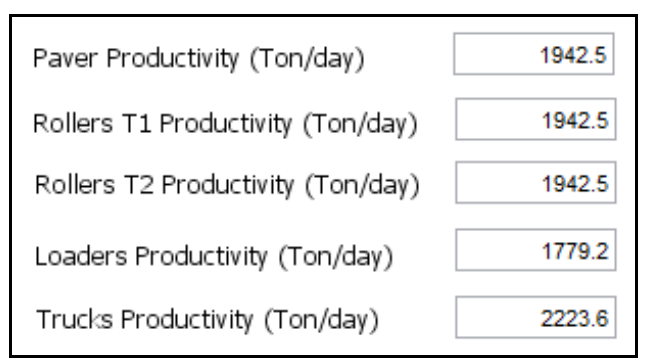

Figure 12: Productivity output measures

The simulator animation module aids in visualizing the progress of each layer and the actions of the equipment as they operate on site. 


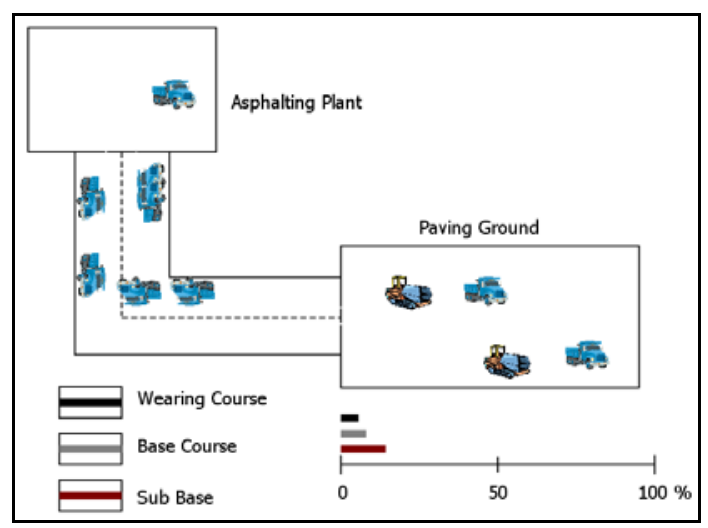

Figure 13: Process animation and layer progress

\subsubsection{Alternative Method}

The model discussed above proved to be very useful in estimating, planning and managing asphalt paving operations for construction projects. However, the development process of the model was quite rigorous and required a great deal of effort and time. It took nine man-months to research the functional requirements (including site visits and subject matter expert interviews), model the problem in a generic manner to make the simulator useable on different asphalt paving projects, develop and program the model using a simulation environment, pilot-test it on a live construction scenario, refine the model, and implement on a live site. Five man-months of the total time went into the modeling and development of the simulator. That is much more time than is usually available to answer important ad-hoc questions which arise during estimation or execution of a project. In such situations, and where pre-existing models fit to help answer those questions do not exist, stakeholders are reluctant to use simulation, and frequently resort to traditional techniques - even though they're inadequate - to help solve their problems. Those techniques are familiar to them and can usually deliver answers quickly. To motivate those stakeholders in construction to take the simulation route, simulation has to become a more accessible tool by (1) diminishing the simulation skill requirements, and (2) significantly reducing the effort and time required to build construction simulation models.

After abstracting the real world processes, implementing them as a simulation model is a time consuming task which requires simulation expertise and skills not readily available to stakeholders on construction projects. The proposed alternative methodology being researched is a move from the classical model building approach to a potentially faster, more accessible method. The objective is to build a typical, generic simulation environment which would take away from the rigor of developing a simulation model by allowing the user, for specific construction simulation models and instead of building a simulation model from scratch inside a simulation modeling environment, to (1) populate specific modular data structures with process information, product information and environmental information; (2) process the data using an algorithm which will compile the provided product, process, and environmental information into suitable simulator inputs; (3) feed the inputs into the generic DES model, which will replicate a complete independent DES task unit for every input data record with the appropriate relevant parameters and resource requirements; and (4) run the replicated set of independent tasks as a whole DES model. The process definition structure component would carry (1) the definitions of the activities to be simulated including all their relevant properties, (2) the inter-activity relationships, and (3) resource definitions and timelines. The product definition structure component would carry (1) the definitions of the objects to be constructed including all their relevant properties, and (2) the object hierarchy to enable level of detail shifting during simulation execution when needed. The environment definition component would carry the definitions of environment aspects affecting productivity (i.e. calendar, season, shifts, etc.) 
Labban, AbouRizk, Haddad, and Elsersy
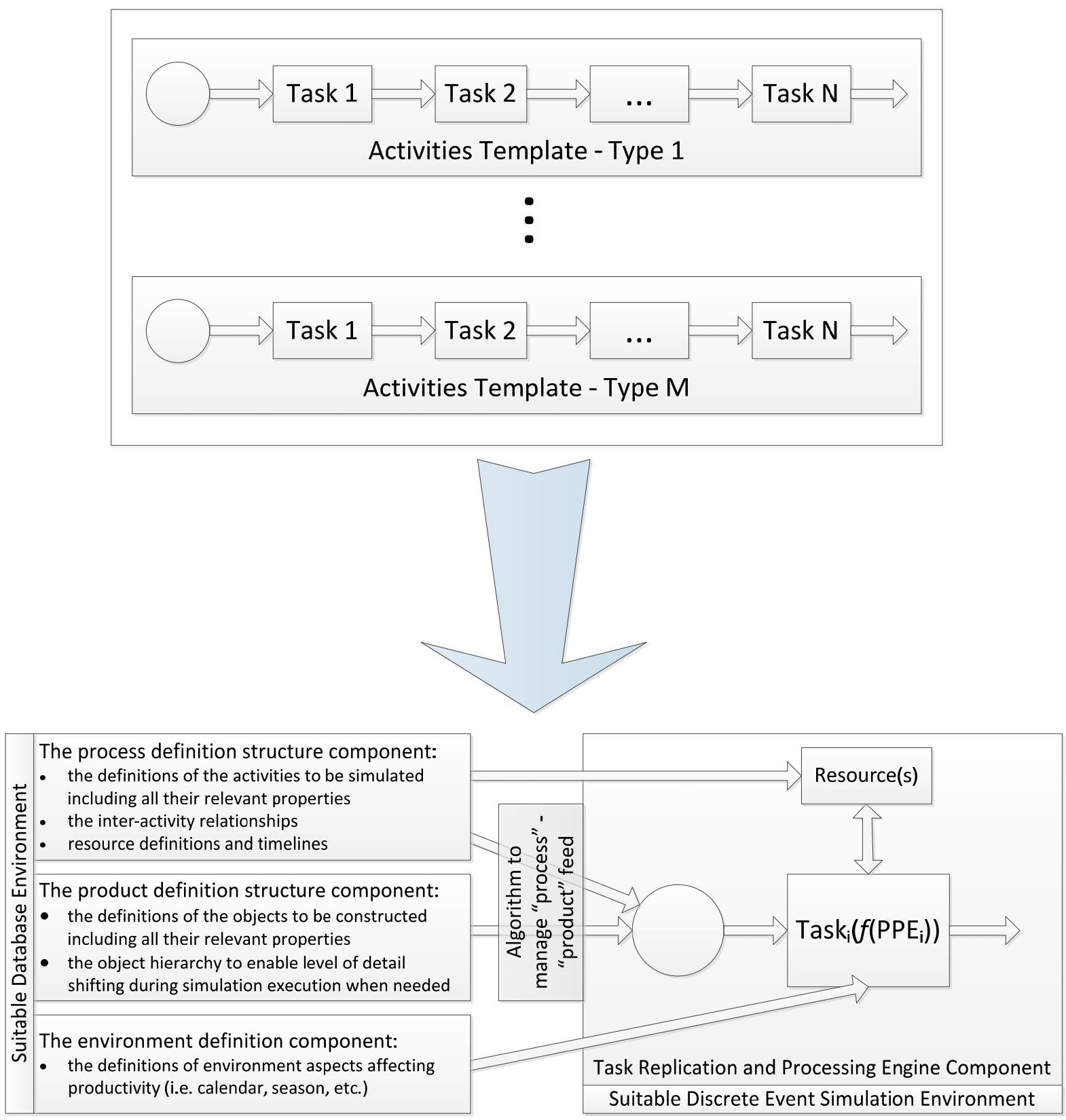

Figure 14: A move from the classical model building approach

\section{DISCUSSION}

\subsection{Possible Benefits}

The proposed methodology describes a new approach for creating construction simulation models with potential benefits to target user groups, including:

1. Enabling target users to build special purpose simulation models quickly and with little simulation model development skills.

2. The proposed approach may allow integration with other construction management systems by allowing simulation flows to be dynamically constructed using data. 


\subsection{Future Work}

The proposed alternative methodology is still a very theoretical approach, in its early stages, and which needs to be developed, implemented and evaluated. Immediate future work will include:

1. Examining diverse construction simulation model building efforts to gather more information and data.

2. Further development of the conceptual model.

3. Further classification of the appropriate target user group(s).

4. Developing the modular input data structure components.

5. Identifying the appropriate simulation environment in which to apply it.

6. Verification and validation using real world test cases.

\section{CONCLUSION}

This paper presented the thinking behind developing a new framework for making the process of building simulation models more accessible to stakeholders without simulation expertise. The framework proposes identifying a common set of data structures that will carry product, process and environmental information, developing an algorithm that can compile that data into suitable inputs for simulation, and developing a generic discrete event simulation engine capable of self-replication and processing of the input data to produce a typical DES history of the model. The main potential benefit of the framework is enabling target users to build simulation models quickly and with minimal simulation model building skills. Further work is still needed to develop the framework and implement it on real world test cases.

\section{ACKNOWLEDGEMENTS}

The asphalting model described in this paper was developed and implemented at Consolidated Contractors Group (CCC) to aid in estimating, planning and managing asphalting operations on major road construction projects.

\section{REFERENCES}

AbouRizk, S. 1995. "Automating the Process of Building Simulation Models." In Proceedings of the 1995 Winter Simulation Conference, Edited by C. Alexopoulos, K. Kang, W. R. Lilegdon, and D. Goldsman, 1032-1038. Piscataway, New Jersey: Institute of Electrical and Electronics Engineers, Inc.

AbouRizk, S. 2010. "Role of Simulation in Construction Engineering and Management." ASCE Journal of Construction Engineering and Management 136:1140-1153.

AbouRizk, S., and D. Hajjar. 1998. "A Framework for Applying Simulation in the Construction Industry." CSCE Canadian Journal of Civil Engineering 25: 604-617.

Anylogic. Nd. The Big Book of Anylogic. Accessed April 14, 2013. http://www.anylogic.com/the-bigbook-of-anylogic.

Caterpillar Inc. 2001. Caterpillar Performance Handbook. $32^{\text {nd }}$ ed. Edmonton: Caterpillar Inc.

Hajjar, D., and S. AbouRizk. 2000. "Application Framework for Development of Simulation Tools." ASCE Journal of Computing in Civil Engineering 14: 160-167.

Hajjar, D., and S. AbouRizk. 2002. "Unified Modeling Methodology for Construction Simulation.” ASCE Journal of Construction Engineering and Management 128: 174-185.

Institute of Electrical and Electronics Engineers (IEEE). 2000. IEEE Standard for Modeling and Simulation $(M \& S)$ High Level Architecture (HLA) - Framework and Rules. New Jersey: Institute of Electrical and Electronics Engineers, Inc.

Mohamed, Y., and S. AbouRizk. 2005. "Framework for Building Intelligent Simulation Models of Construction Operations." ASCE Journal of Computing in Civil Engineering 19(3), 277-291. 
Peurifoy, R. L., and C. Schexnayder. 2001. Construction Planning, Equipment, and Methods. 6th ed. Columbus, OH: McGraw-Hill.

Sawhney, A., and S. AbouRizk. 1996. "A Computerized Tool for Hierarchical Simulation Modeling." ASCE Journal of Computing in Civil Engineering 10: 115-124.

Shi, J., and S. AbouRizk. 1998. "An Automated Modeling System for Simulating Earth-moving Operations." Microcomputers in Civil Engineering, Journal of Computer-Aided Civil and Infrastructure Engineering 13: 121-130.

Shi, J., and S. AbouRizk. 1997. "Resource-Based Modeling for Construction Simulation." ASCE Journal of Construction Engineering and Management 123: 26-33.

Wang, P., and S. AbouRizk. 2009. "Large-scale Simulation Modeling System for Industrial Construction." Canadian Journal of Civil Engineering 36:1517-1529.

Yin, C. 2003. "Toward a Pattern Language for Discrete Event Simulation.” M.Sc. thesis. Univ. of Alberta, Edmonton, Alta., Canada.

Zeigler, B. P., H. Praehofer, H., and T. G. Kim. 2000. Theory of Modelling and Simulation. 2nd ed. Academic Press.

\section{AUTHOR BIOGRAPHIES}

RAMZI LABBAN is a $\mathrm{PhD}$ candidate in Construction Engineering and Management at the Department of Civil and Environmental Engineering, University of Alberta. He is also Manager of Computer Modeling and Simulation at Consolidated Contractors Company (CCC). His email address is labban@ualberta.ca.

SIMAAN M. ABOURIZK holds an NSERC Senior Industrial Research Chair in Construction Engineering and Management at the Department of Civil and Environmental Engineering, University of Alberta, where he is a Professor in the Hole School of Construction. He received the ASCE Peurifoy Construction Research Award in 2008. His email address is abourizk@ualberta.ca and his web page is http://www.irc.construction.ualberta.ca.

ZUHAIR HADDAD is vice president, corporate affairs, and chief information officer for CCC. He is in charge of mapping out and implementing IT and communication strategies and manages the information systems, communication, and E-procurement departments. He also oversees the plant department, managing CCC's extensive fleet of construction equipment. His work experience includes several construction projects in Saudi Arabia. He has interests in developing 3D-based construction controls software. He holds a civil engineering degree from $\mathrm{Cal}$ State-Chico and a master's in construction management from Stanford University.

AMR EL-SERSY holds a Ph.D. degree in Engineering and Construction Management from the University of California at Berkeley. He has over 20 years of experience. Currently, he is the Group Manager Learning and Innovation at Consolidated Contractors Company (CCC). He is responsible for the strategy and implementation of corporate-wide Knowledge Management program as well as many innovative ideas and R\&D initiatives. Prior to this assignment, he was deputy General Manager for the EPC oil \& gas business unit of CCC. Earlier, he was the Manager of Engineering and Construction systems group where his responsibilities included overseeing the implementation of different engineering, procurement and construction IT systems. He led the development of several corporate initiatives such as the Enterprise Risk Management program. Before joining $\mathrm{CCC}$, he held several project management positions with international general contractors and construction management consulting firms. 